\title{
Cefalea en racimos
}

Dentro de las causas de cefalea primaria está la Cefalea en racimos o Cefalea de Horton en el idioma inglés conocida como "Cluster headache". Las características diagnósticas fueron mencionadas por la Sociedad Internacional de Cefalea (IHS, por sus siglas en inglés) en 1988, en donde su donación, intensidad y síntomas acompañantes son llamativas.

El médico general y en especial el médico de urgencias tarde o temprano se van a encontrar con esta entidad y su capacidad de reconocerla y aún más de ofrecerle opciones terapéuticas efectivas al paciente (Oxígeno, Triptanes de acción rápida y tratamiento profiláctico como el Verapamilp y el Carbonato de Litio) son profesionalmente satisfactorios.
El artículo Cefalea en Racimos de los Doctores J.A. van Vliet, J. Haan, M. D. Ferrari, E. Kors, J.M. Peralta, F. Chaves-Sell, H. Raventós, nos da los lineamientos en reconocer esta entidad, su diagnóstico diferencial, comprender las bases fisiopatológicas y en el tratamiento que es lo recomendado y lo no recomendado con el conocimiento actual.

Artículo con lenguaje claro y útil en nuestra práctica clínica diaria.

\author{
Dr. Alexander Parajeles Vindas \\ Médico Neurólogo HSJD, \\ Coordinador Postgrado en Neurología \\ San José, Costa Rica.
}

